\title{
Ni/W/SBA-15 catalyst for Carbon dioxide reforming of methane
}

\author{
J. Huang ${ }^{1, a}$, Jienan Zhang ${ }^{2, b}$ and Yue Zhang ${ }^{3, c}$ \\ ${ }^{1}$ Yuncheng University, Yuncheng, 044000, Shanxi, China \\ ${ }^{2}$ Shanxi Normal University School Of Chemistry And Material Science, 041000,Shanxi, China \\ ${ }^{3}$ Wuhan University, Wuhan, 430070, Hubei, China

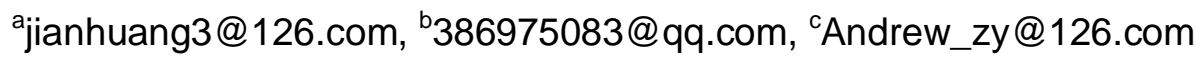

\begin{abstract}
Keyword: SBA-15 mesoporous molecular sieve, $\mathrm{CO}_{2}$-reforming,Ni/W metal oxides, Ni/W based catalysis
\end{abstract}

Abstract.Carbon dioxide reforming of methane over Ni/W/SBA-15 catalyst was studied. The catal yst was characterized by X-ray diffraction, IR analysis, SEM and TD-DTA.The results indicated that Ni/W/SBA-15 catalyst typical mesoporous structure, uniform aperture, and only after the metal into the carrier SBA-15, part of the distributed on the hole wall surface, part of the natural dispersion in molecular sieve hole, after $800 \square$ high temperature reaction, catalyst, although some sintering activity decline, but most are still able to maintain higher activity.

\section{Introduction}

In 1998, zhao etc. ${ }^{[1]}$ in three block polymer as the template agent synthesized for the first time the SBA-15 mesoporous molecular sieve. This is a new type of mesoporous materials, it has a unique two-dimensional six-party mesoporous molecular sieve hole structure, orderly aperture, hole wall thick, good thermal stability and hydrothermal stability, high specific surface area, and found that this kind of molecular sieve pore size in the larger range $(4.6-30 \mathrm{~nm})$ is adjustable, to a certain extent,SBA-15 improved the defects of conventional mesoporous molecular sieves, for example, conventional thermal stability and hydrothermal stability of molecular sieves are relatively poor, the new synthesis SBA-15 expanded the molecular sieve in the field of catalysis, energy storage efficiency and other fields of application range .

All silicon SBA-15 molecular sieve materials are no catalytic activity center, because it is made of the silica structure, this limits its applications in catalysis, so people often introduce different performance of atoms or molecules, metal ions, for example, it can improve the hydrothermal stability of the molecular sieve at the same time, on the surface of the acid, alkaline and REDOX ability, make this kind of molecular sieve has a certain catalytic activity center, and then used in the catalytic reaction $^{[2]}$, because of the SBA-15 itself aperture adjustable performance is very good to control the size of the metal particles, limit metal ions, grow up.Therefore, in recent years, scientists the SBA-15 as the carrier, the introduction of different atoms or molecules, nano-sized catalyst, so as to explore its potential applications in the field of materials and catalysis.

Methane and carbon dioxide reaction generates carbon monoxide and hydrogen is energy storage and conversion rate of more than $90 \%$ when temperature is $800 \square$, the catalyst can improve the conversion rate of the reaction, however, nickel-based catalysts sintering at $800 \square$ and carbon deposition, resulting in a decline in catalyst activity.Ni/W metal oxide load SBA-15 molecular sieve catalyst, remains a highly active at high temperature. 


\section{Experimental}

\section{Catalyst preparation}

Add the additives of Ni/W/SBA-15 by immersion method. Proportional to the mixed fertilizer (Nickel nitrate $\left[\mathrm{Ni}\left(\mathrm{NO}_{3}\right)_{2} \cdot 6 \mathrm{H}_{2} \mathrm{O}\right]$, ammonium paratungstate $5\left(\mathrm{NH}_{4}\right)_{2} \cdot \mathrm{O} \cdot \mathrm{WO}_{3} \cdot 5 \mathrm{H}_{2} \mathrm{O}$ followed by stirring, aging, drying, and calcining of the sample at $450 \square$ for $6 \mathrm{~h}$ to form Ni/W/SBA-15. The catalyst components in terms of percentage by weight were $12 \mathrm{wt} \% \mathrm{Ni}, 3 \mathrm{wt} \% \mathrm{WO}_{3}$ and $6 \mathrm{wt} \% \mathrm{WO}_{3}$, $9 \mathrm{wt} \% \mathrm{WO}_{3,}, 12 \mathrm{wt} \% \mathrm{WO}_{3}$, Marked as SNW1, SNW2, SNW3, SNW4, respectively.

\section{Catalyst characterizations}

XRD patterns were recorded on a Rigaku D/max 2250 powder X-ray diffraction with monochromated $\mathrm{Cu}-\mathrm{K} \alpha(40 \mathrm{kV} / 100 \mathrm{~mA})$ radiation. $2 \theta$ angles ranged from 10 to 80 with a speed of $8 \%$ min. Nitrogen physisorption was measured on a NOVA2200e (American, contador)at a temperature of $196 \square$. Around $200 \mathrm{mg}$ samples were degassed at $200 \square$ during $2 \mathrm{~h}$ under $20 \mu \mathrm{m} \mathrm{Hg}$ prior to adsorption. Nitrogen physisorption was measured on a TENSOR27(German, brooke) at a temperature of $196 \square$. Around $0.2 \mathrm{~g}$ samples were degassed at $200 \square$ during $2 \mathrm{~h}$ under $20 \mu \mathrm{m} \mathrm{Hg}$ prior to adsorption. SEM image was obtained on a Hitachi S-4800 microscope operated at $15 \mathrm{kV}$. FT-IR spectra were recorded using a TENSOR27 spectrometer. The range in wave number was $400-4000 \mathrm{~cm}^{-1}$. The amount of carbon deposited on the catalysts was determined on a PerkinElmer TG/DTA instrument under air atmosphere.

\section{Results and discussions}

\section{XRD analysis}

Fig.3-1 as the response spectra of sample before, in the figure. XRD wide Angle diagram, Fig.3-1 in 2 theta equals $23.36^{\circ}$ has a more gentle diffraction peak, is the characteristic peak of $\mathrm{SiO}_{2}$ carrier SBA- $15^{[3]}$, in addition, respectively in 2 theta equals $37.5^{\circ}$ and $43.4^{\circ}$ and $63.0^{\circ}$ appeared strong diffraction peak, $75.6^{\circ}$ in a less obvious diffraction peak, it is the typical characteristic peak of $\mathrm{NiO}$.The first three kurtosis is stronger, illustrate the $\mathrm{NiO}$ grain is bigger and the dispersion is not good.Sample 2 and 4 in there is an obvious feature of $31.04^{\circ}$ diffraction peak, it is the characteristic diffraction peak of $\mathrm{W}^{6+[4]}$.

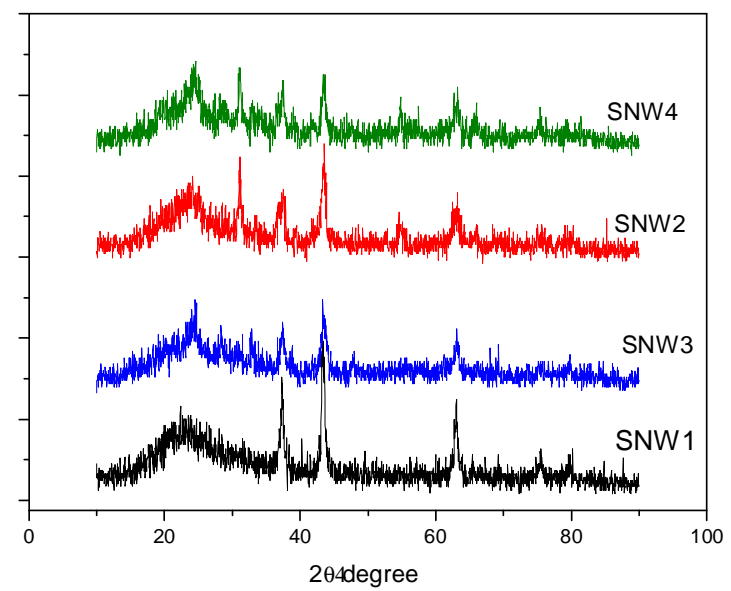

Fig.3-1 Wide-angle XRD patters of the fresh Ni/W/SBA-15 samples

Fig.3-2 for the response spectra of samples, you can see the sample 1,4,2 there is a obvious $\mathrm{SiO} 2$ diffraction peak, sample 2 and 4 in 2 theta $=44.12^{\circ}, 48.48^{\circ}$ and $51.44^{\circ}$ there is obvious diffraction peak, 
there is a near 2 theta equals $75.32^{\circ}$ diffraction peaks of the weak, the diffraction peak is reaction after samples Ni (111) diffraction characteristic peak. Sample 1 in 2 theta equals $44.12^{\circ}$ and $51.68^{\circ}$ nearby have a characteristic peak of $\mathrm{Ni}(111)$. But the sample $3 \mathrm{Ni}(111)$ of characteristic peak disappear entirely, but near 2 theta equals $22.61^{\circ}$ appear obvious peak, this may be the catalyst after reaction caused by carbon deposition. Near the theta $2=7.97^{\circ}$ is an interference of absorption peak.

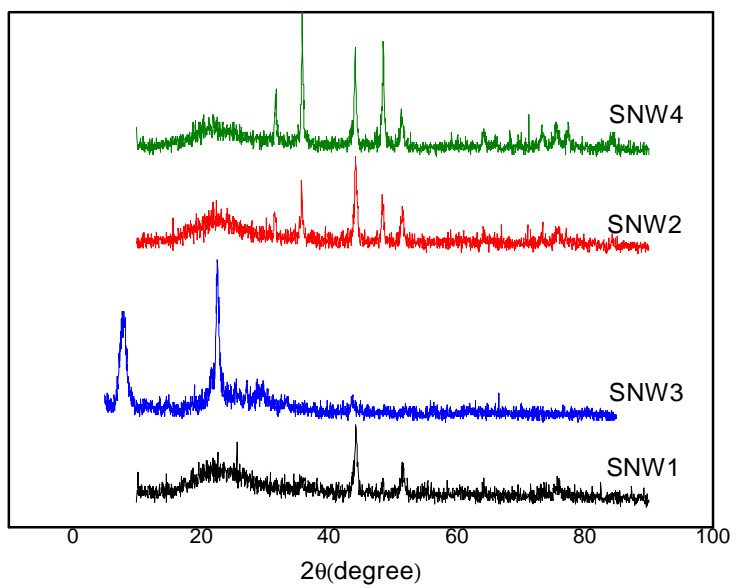

Fig.3-2 Wide-angle XRD patters of the used Ni/W/SBA-15 samples

\section{FT-IR analysis}

Fig.3-3 for synthetic samples before the reaction of FT-IR spectra.By figure.3-3,Ni/W/ SBA-15 in $3500-3000 \mathrm{~cm}^{-1}$ has a wide range of absorption peak, the peak is characteristic of hydroxyl absorption peak, exists in the SBA-15 molecular sieve surface; Nearby the absorption peak of $1091 \mathrm{~cm}^{-1}$ belongs to $\mathrm{Si}-\mathrm{O}$ in the tetrahedron $\mathrm{Si}-\mathrm{O}-\mathrm{Si}$ asymmetric stretching vibration peak; The absorption peak near $806 \mathrm{~cm}^{-1}$ for $\mathrm{Si}-\mathrm{O}$ the $\mathrm{SiO}_{4}$ tetrahedron bending vibration peak, $468 \mathrm{~cm}^{-1}$ the characteristic peak is near the skeleton $\mathrm{Si}-\mathrm{O}$ key bend stretching vibration.And the absorption peak near $958 \mathrm{~cm}^{-1}$ should belong to the skeleton of W-O-Si or Ni-O-Si key vibration, the absorption peak is not obviously.

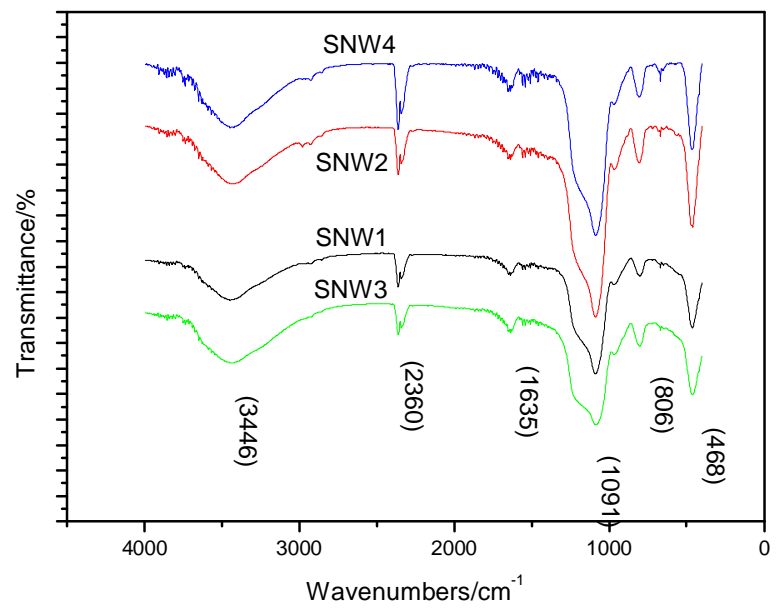

Fig.3-3 IR patterns of the fresh Ni/W/SBA-15 
Fig.3-4 samples for synthetic reaction after the infrared spectrogram. Four samples in the 470 $\mathrm{cm}^{-1}, 810 \mathrm{~cm}^{-1}, 1103 \mathrm{~cm}^{-1}, 3440 \mathrm{~cm}^{-1}$ the absorption peak near to illustrate four reaction after the samples are complete for carrier SBA-15 molecular sieve frame structure was not damaged.

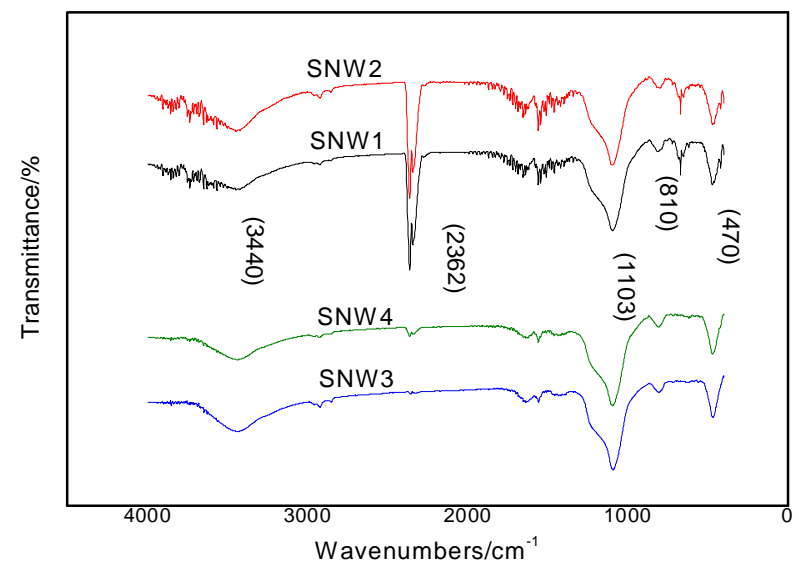

Fig.3-4 IR patterns of the used Ni/W/SBA-15

\section{SEM analysis}

Fig.3-5 reaction before the different content of Ni/W/SBA-15 scanning electron microscopy (sem), surface topography is rod can be seen in the figure, or shape is like a big grain of rice, can clearly see some particle shape on the rod surface, these particles is in the shape of the load on the SBA-15
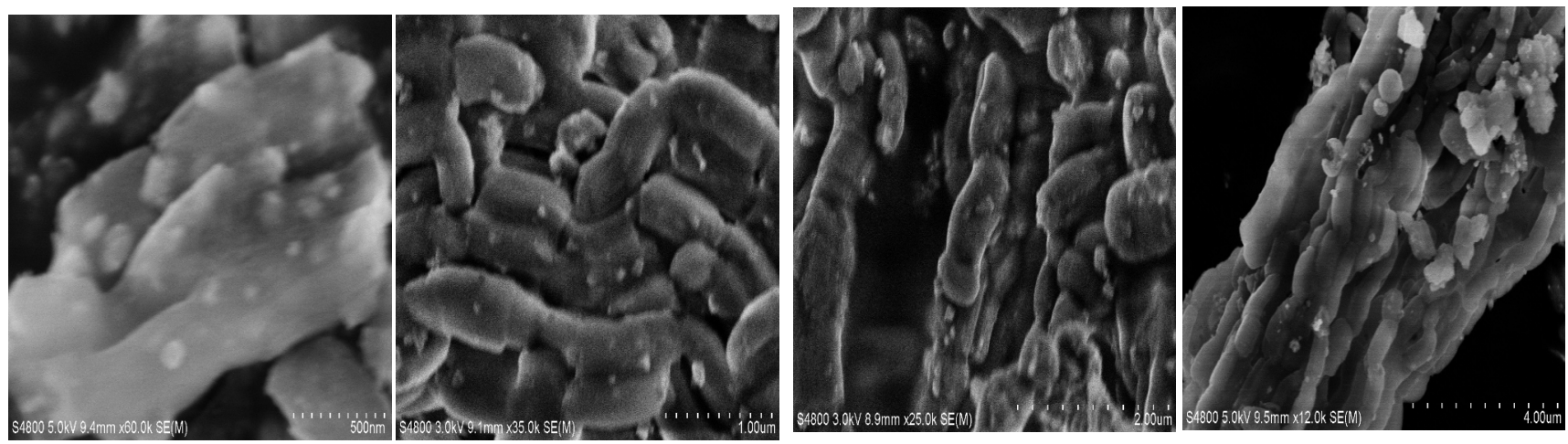

metal $\mathrm{Ni}$ and $\mathrm{W}$, can also be observed that these particles are not reunite together, but distributed in SBA-15 hole wall surface, and is also likely to enter the SBA-15 molecular sieve in the channel.

(A)

(B)

(C)

(D)

Fig.3-5 SEM of the fresh Ni/W/SBA-15 samples
(A)SNW1
(B)SNW2
(C)SNW3
(D)SNW4

Fig.3-6 is the electron microscope scan of the sample after reaction, will not be able to clearly see the separate stick like before the reaction, the group that only, this is the catalyst after reaction sintering, (B) in molecular sieve can be found in the cave, but I still can see the complete rod, can clearly see the load in the (D) of metal particles, shows that after reaction, the catalyst still remained active part, not completely the deactivation degeneration. 

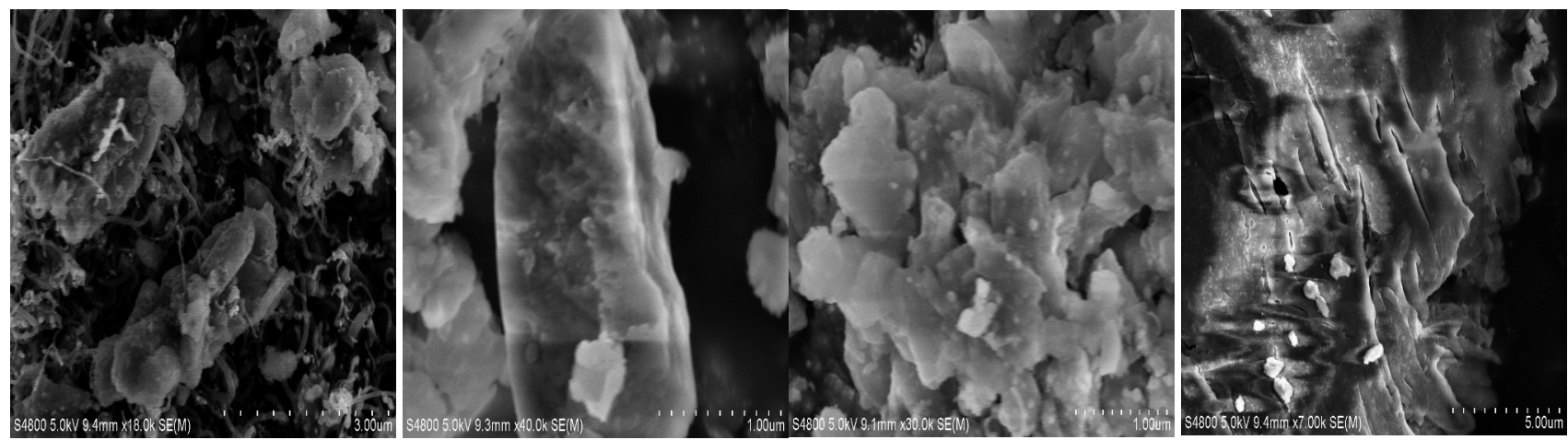

(A)

(B)

(C)

(D)

Fig.3-6 SEM of the used Ni/W/SBA-15 samples
(A)SNW1
(B)SNW2
(C)SNW3
(D)SNW4

\section{TG analysis}

Fig.3-7 for reaction after Ni/W/SBA-15 TG curve, can be seen from the curve of SNW1 total weight loss of about $5.1 \%$, at $400 \square$ below zero gravity is $3.3 \%$, the range of $400 \square$ to $400 \square$, the curve is gentle, can be thought of not weightless, $1.8 \%$ of the $550 \square$ to $900 \square$ weightlessness. To attain maximum rate of temperature is $293 \square$.

From SNW2 curve can be, with a total of about $2.7 \%$, at $400 \square$ below zero gravity was $2.7 \%$, and $400 \square$ to $900 \square$ can be thought of not weightlessness. Can be thought of under $400 \square$ of weightlessness is caused by two reasons, because inside the molecular sieve containing moisture, the moisture loss caused, because inside the hole there are a lot of hydroxyl groups, the hydroxyl dehydration condensation occurred.

According to SNW3 curve, can know total weight loss of about $7.1 \%$, at $400 \square$ below zero gravity was $3.1 \%, 5.0 \%$ of the $400 \square$ to $900 \square$ weightlessness. To attain maximum rate of temperature is $609 \square$.SNW4 curve in general, the weightlessness is zero, there is no obvious change.But weightlessness happened under $400 \square$, about 2.0\%.This shows that high levels of molecular sieve pore load $\mathrm{W}$ is more, cause the sample absorption interference caused by too much water.

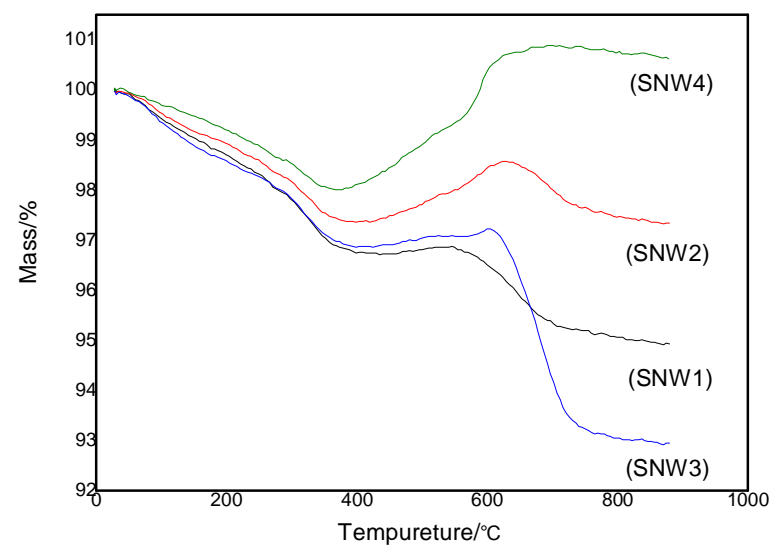

Fig.3-7 TG traces of the used Ni/W/SBA-15 samples 
As shown in fig.3-8 samples for reaction after Ni/W/SBA-15 of the DSC curve, when the curve drops, numerical value is negative, that is endothermic reaction, such material decomposition, when rising curve, that is exothermic reaction, then material burning. Thus, SNW1, SNW2, SNW3, SNW4 are all first endothermic decomposition, and then the combustion heat release.

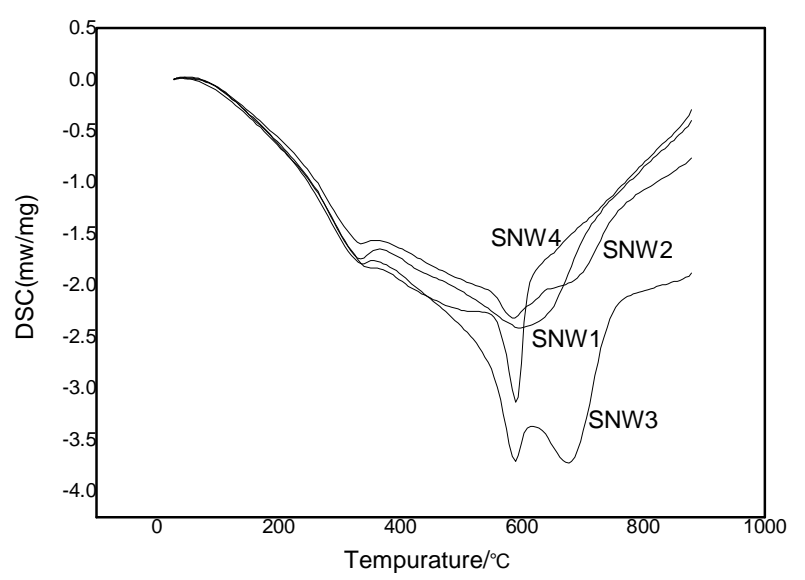

Fig.3-8 DSC traces of the Ni/W/SBA-15 samples

\section{Conclusion}

(1)Respectively load $3 \mathrm{wt} \% \mathrm{~W}, 6 \mathrm{wt} \% \mathrm{~W}, 9 \mathrm{wt} \% \mathrm{~W}, 12 \mathrm{wt} \% \mathrm{~W}$ of Ni/W/SBA-15 of catalyst, make it under the condition of $800 \square$ high temperature reaction, reaction after the characteristics of the XRD diffraction peak still exists, that still maintain the activity of the catalyst, but $9 \mathrm{wt} \% \mathrm{~W}$ carbon deposition.

(2)the FT-IR in before and after the reaction, the characteristics of the functional mesoporous molecular sieve absorption peak all exist, that after the reaction carrier SBA-15 functional groups still exist for mesoporous molecular sieve, structure intact.

(3) the shape of the Ni/W/SBA-15 as big grain of rice, a typical structure of mesoporous molecular sieves, aperture only and uniform, but $\mathrm{WO}_{3}$ on carrier SBA-15 distribution is not uniform, but a part of the distributed on the hole wall surface, part of the natural dispersion in molecular sieve pore channels.After $800 \square$ high temperature reaction, can still very good catalyst activity.

\section{Acknowledgements}

The authors gratefully acknowledge the financial support from the The Natural Science Fund of Shanxi (2013011009-3), the Shanxi Scholarship Council of China (2013-105) and The Yuncheng Univercity Fund of Shanxi (YQ-2013010,CY-2012017).

\section{References}

[1]Zhao Dongyuan, Feng Jianglin, Huo Qisheng, et al.Triblock Copolymer Syntheses of Mesoporous Silica with Periodic 50 to 300 Angstrom Pores[J]. Science,1998,279(5350),548-552. [2]Xiao Yihong, Shen Xiaonv, Zheng Ying et al. Pt/Ce/Ni-SBA-15 mesoporous molecular sieves synthesis and performance research [J]. Journal of functional materials, 2007.10 (38)

[3]Song Yan.Load metal SBA-15 mesoporous materials preparation, characterization and 
performance study [D]. Liaoning normal, 2012.

[4]Cao Yueling, Wang Junwei, Li Qifeng et al. Ni-WO3/SBA-15 on cellulose hydrolysis catalyst hydrogenation $[\mathrm{J}]$. Journal of combustion chemistry, 2013-8.41 (8). 